\title{
Towards a Policy on Assessment Methodology for Malagasy Students at the Universite Des Mascareignes
}

\author{
Betchoo Nirmal Kumar (DBA) \\ Université des Mascareignes, Republic of Mauritius
}

Doi: 10.19044/esj.2017.v13n28p358 URL:http://dx.doi.org/10.19044/esj.2017.v13n28p358

\begin{abstract}
With an increase in the intake of foreign students to the Universite des Mascareignes (UdM), there are arguments on reviewing the assessment system in force in the university. It might be correct to assume that universities have the flexibility of providing various forms of assessments but these have to be tailored to the needs of contemporary students. The research is based on the fact that Malagasy and foreign students coming from the African region have different educational backgrounds that differ from the Mauritian Anglo-Saxon inherited system with formal examinations and a little change in evaluations recently. The fact that foreign students are now an integral part of the university revealed that Malagasy students, taken as a sample of the research, tended to favour the use of French language and appeared to be more versed in practical applications of learning provided by the UdM. This situation puts them in slight confrontation with Mauritian students who are more apt to learn by heart and assimilate English language without much difficulty. In view of this situation, the researcher claims that it might be possible to make assessments more flexible and adaptable to such foreign students while confirming that the essence of formal examinations should be maintained. This approach could be more practical as evaluation suited to the needs and of foreign students at the UdM.
\end{abstract}

Keywords: Assessment, Malagasy Students, Flexible, Education, University

\section{Introduction:}

In a university setting that favours more of an Anglo-Saxon system of assessment, little is said of changing the assessment methodology when it comes to evaluating foreign students whose mother tongue is not English. Apparently, with the formal system of assessments mainly in English, Malagasy students coming in increasing numbers to the Université des Mascareignes (UdM) might be disadvantaged both in learning and 
assessment. The rate of failure of first year students in business management at the UdM claims that Malagasy students reach a significant failure rate at the level of single modules and at the semestral examination. With an average score of $45 \%$ for a sample of Year 1 Malagasy students and a significant rate of failure at the end of the academic semester, there is a clear problem regarding the education and assessment system in force at the university. The issue here is that the Malagasy student is disadvantaged when it comes to assessing him in an English-based system. Weak scores in final year examinations attest the low conversance of such students with Englishbased examinations (Betchoo, 2017). This might raise the question of reviewing or improving assessment methods for foreign students.

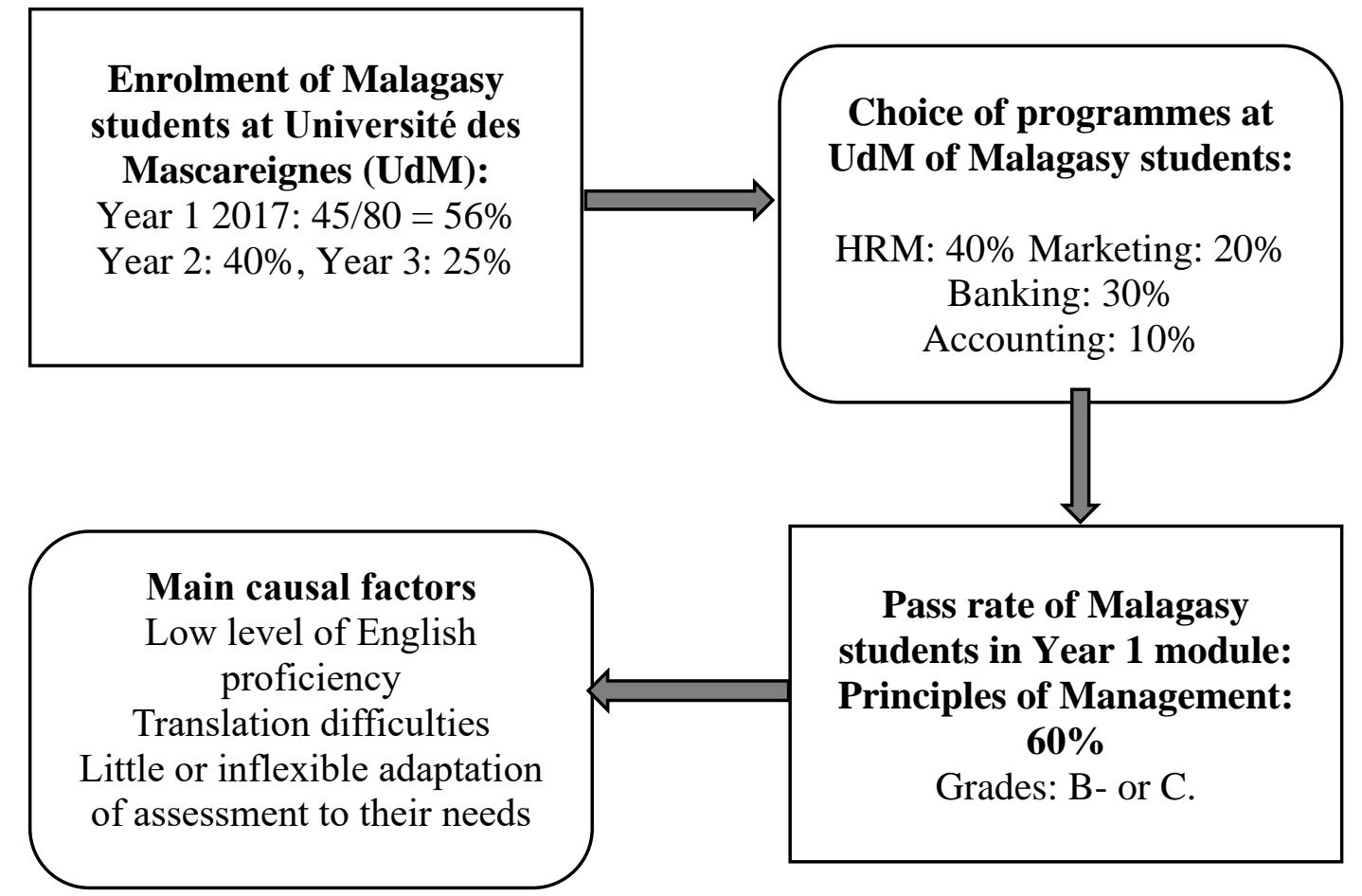

Chart 1: Diagrammatic illustration of the situation of Malagasy students at the UdM.

\section{Brief literature review:}

Despite their high abilities, international students arriving on the university campus often face serious challenges to sustaining their good academic performances. They often have difficulty taking tests (memorisation vs. formulating their own ideas), reading material for courses, following a set curriculum and registering and understanding the American grading system (Breuder, 1972; Amoh, 1984; Leong \& Sedlacek, 1989; Mau \& Jepsen, 1990 \& Razavi, 1988). 
Beasley and Pearson (1996) argue that the assumption that university students naturally possess competencies that will enable them to be successful in their tertiary studies is cast into doubt by the evidence of their study. Pilote (2007) observed that the academic problems of the international students are clearly tied to language adaptation to the medium of instruction. Antanaitis (1990) who pointed out that a language deficiency is the major academic obstacle for the international students.

Regarding learning difficulties of foreign language, Ganschow and Schenider (2006) commented that the primary difficulty for at-risk foreign language learners most likely originates in the phonological/orthographic (sound-symbol), and sometimes, syntactic, areas of language rather than the semantic area. Their difficulties often become apparent in the first semester of a foreign language course. Students with low levels of sound-symbol and grammatical skills tend to have problems with most aspects of foreign language learning-listening, speaking, pronunciation, reading, and writing (Ganschow and Schenider, 2006). Burke and Wyatt Smith (1996) supported the argument on stating that language related difficulties are likely to be greater if the University students have to use a language that they have not used as a medium of instruction in their previous education.

It is then important to see how students whose mother tongue (L1) is not English could be assessed alternately. The level of proficiency is not necessarily the same for all four dimensions-listening comprehension, speaking skills, reading comprehension and writing skills-and there can be differences between languages or learning based on the individual's sociocultural background, environment and needs or interests (Levai et al, 2009). Universities should provide quick learning opportunities for students to adapt themselves to the foreign countries mother tongue. Welikala (2015) states that curricula should encourage students to improve multiple perspectives, know more about alternative ways of learning-both western and nonwestern. Over emphasis as well as complete ignorance about different cultures of learning can both be harmful.

\section{Literature Gap:}

There is a gap in the literature which does not ideally reflect how to tailor assessments. For example, has there been an evaluation of the needs of Malagasy students in a Mauritian context like the UdM? The argument is that Malagasy students might only learn and be proficient with the use of English over the years of study at the UdM but little has been so far said of assessing students fairly and consistently in their initial year. This is the challenge that requires lecturers' commitment to vary their teaching and assessment accordingly without compromising university standards of education. 


\section{Research Questions:}

Four research questions were addressed in this survey. Two main questions: Q1 and Q2 were targeted to the students. The two other questions (Q3 and Q4) were targeted to the course providers. For the second set of questions, selected samples were from lecturers servicing business courses in Human Resource Management, Marketing and Banking. An informal method with open-ended questions and discursive arguments applied to Q3 and Q4.

Q1: Are there tangible learning and assimilation difficulties for Malagasy students in UdM courses?

Q2: Is the current assessment done suited to the needs of Malagasy students?

Q3: Is it possible to alternate English and French in assessing Malagasy students?

Q4: Can assessment be tailor-made for Malagasy students using the two official languages in the Mauritian educational system?

\section{Research Sample and Methodology:}

The sample is a quasi-random one comprising full-time Malagasy students in all streams from year 1 to year 3. There was greater focus on Year 1 students who embark on courses and find much difficulty to learn and assimilate English language. A sample of 50 students could be considered due to the limited number of foreign students admitted. 36 Year 1 students were chosen and 14 Year 2 and 3 students combined. This was partly linked with the percentage of Malagasy student intakes between 2015 and 2017. It was clear that language difficulties were more evident among new entrants compared to those embarking on Year 2 and beyond. Still there was the argument that responses could be compared between the two samples identified to see whether variances were significant or not regarding research questions posed. At another level, the two remaining research questions were targeted to academic staff at the UdM coming from areas like Human Resource Management, Marketing and Accounting. Further feedback was recorded from participants in a presentation at the conference proceedings of the Mauritius Institute of Education Research Week 2017.

\section{Research Findings:}

The first research question addressed tangible learning and assimilation difficulties for Malagasy students. For this purpose, the random sample gathered ideas from Year 1 students and combined those of Year 2 and 3 given that this category had mastered English concepts far better than beginners. The findings are presented below: 


\section{Teaching and learning difficulties}

A chi-square statistic was first used to test significance in terms of difficulties faced by Malagasy students to learn English. A Yes/No question was asked. Note that there was a larger sample of first year students because there has been over 50\% of new recruits from Malagasy Republic in 2017 compared to a mere $20 \%$ in the past years.

Table 1: Chi-square test concerning learning difficulty in English language for Malagasy students

\begin{tabular}{|c|c|c|c|}
\hline & $\begin{array}{l}\text { Difficult to learn } \\
\text { English }\end{array}$ & $\begin{array}{l}\text { Not difficult to } \\
\text { learn English }\end{array}$ & $\begin{array}{l}\text { Marginal } \\
\text { Totals }\end{array}$ \\
\hline Year 1 students & $24(20.16) \quad[0.73]$ & $12(15.84) \quad[0.93]$ & 36 \\
\hline Year $2 / 3$ students & $4 \quad(7.84) \quad[1.88]$ & $10 \quad(6.16) \quad[2.39]$ & 14 \\
\hline $\begin{array}{l}\text { Marginal Column } \\
\text { Totals }\end{array}$ & 28 & 22 & 50 (Grand Total) \\
\hline
\end{tabular}

The chi-square statistic is 5.94. The $p$-value is 0.0148 . This result is significant at $p<.05$. It means that there is significant difference in perception of Malagasy students in learning English between Year 1 and year2/3 students at the UdM.

A qualitative evaluation adds information to the findings obtained in Q1.

\section{Qualitative Responses \\ Year 1 Students}

To test this hypothesis, students were randomly interviewed regarding their difficulty in learning and assimilating business knowledge offered in the UdM. Some key findings are highlighted below:

'It is difficult for a first-year student to grasp English language as we have been exposed to French mode of teaching.'

'I opted for Business and Finance but seen from the teaching methodology with lots of English vernacular, I am willing to shift to marketing as it might be simpler for me.'

'I do agree that lecturers spare the effort of teaching us correctly but the perception that we are from a different background with a French-based learning culture is not well assimilated by all lecturers. Some prefer sticking to English language.'

'Lecturers must talk slowly and allow us better understand what they are saying. We are happy that some lecturers translate some material in French and also use this language concurrently.' 


\section{Year 2/ 3 Students}

'We are now much better in grasping English language after maturing with the teaching medium at the university.'

'We do get the terminologies right and we try our best to master the concepts taught to us.'

'To better understand a concept, we ask the lecturer to rephrase it. Sometimes, we do paraphrase a concept on our own.'

'I am of the opinion that practice and personal effort do contribute to improved learning in English language over the years at the university although Year 1 remained tedious.'

\section{Evaluation of current assessment at the UdM}

The second question asked for the evaluation of the current assessment done at the Université des Mascareignes. The question asked was whether it was suited to meet the needs of the Malagasy students in the two groups: Year 1 and Year 2/3 combined.

Another test was conducted to see students' perceptions of assessments and examinations at the UdM. Assessments were seen as easier to pass an examination while formal examinations done under supervision was generally viewed as tough. The results are assessed below in the Chisquare table.

Table 2: Chi-square test concerning the preference of evaluation for Malagasy students

\begin{tabular}{|c|c|c|c|}
\hline & Prefer Assessments & Prefer Exams & $\begin{array}{l}\text { Marginal Row } \\
\text { Totals }\end{array}$ \\
\hline Year 1 students & $22(20.16) \quad[0.17]$ & $14(15.84) \quad[0.21]$ & 36 \\
\hline Year $2 / 3$ students & $\begin{array}{llll}6 & (7.84) & {[0.43]}\end{array}$ & $\begin{array}{llll}8 & (6.16) & {[0.55]}\end{array}$ & 14 \\
\hline $\begin{array}{l}\text { Marginal } \\
\text { Column Totals }\end{array}$ & 28 & 22 & $\begin{array}{l}50 \\
\text { Total) }\end{array}$ \\
\hline
\end{tabular}

The chi-square statistic is 1.36 . The $p$-value is 0.243 . This result is not significant at $p<.05$. this implies that there is no significant difference in the preference of evaluation choices. Both groups are aligned to the same perception and evaluations remain consistent for both groups under study.

A qualitative evaluation supports the findings in Table 2.

\section{Qualitative Responses}

\section{Year 1 students}

'Internal assessments are fairly well done since there is flexibility in marking and evaluation. Formal exams at the end of the year look to be tough since they are done without assistance.' 
'The examinations are tough with testing questions. We have difficulty of answering in English. Sometimes, we are left by writing a single line or nothing as an answer.'

'In courses where there are $100 \%$ assessments, we do score satisfactory marks. In examinations, this tendency is just opposite.'

'The examinations do not allow us to respond in French say in a case study while we do have adequate material to write and respond in French.'

\section{Year 2/3 students}

'The assessments are fair in general. Examinations are tough.'

'We have better familiarity with French language though we need to do the effort to read and write English correctly.'

'Assessments in soft skills modules done as part of the curriculum are more convenient to tackle than formal exams.'

'We sometimes seek the help of our lecturer to guide us for our assessments.'

'We are informed that core modules are taught in English and that the onus to perform well depends on us. We have to spare such effort to learn.'

\section{The possibility of alternating English and French in assessing Malagasy students}

This question was addressed to teaching staff at the UdM but also certain information was gathered from a presentation done by the author on $12^{\text {th }}-14^{\text {th }}$ July 2017 at the Mauritius Institute of Education Research Week.

\section{UdM Staff}

'I am agreeable to it to it since we are having a larger intake of Malagasy students year after year. They comprise our target market and the needful should be done with the students. I am willing to offer them such an alternative.'

'Regarding assessment, we do have the flexibility to do so but certain criteria should be respected. Being a bilingual university, one mode of assessment cannot be favoured to the detriment of another one.'

'Since our courses are technical and the terminology is English based from what we have learnt and developed as curricula, it is difficult to shift to French in assessing technical courses.'

'In Law modules, there is the combination of English and French components. Possibly, the option of responding in French to legislation under Code napoleon (French system) might apply. For other situations, English-based law requires a knowledge and mastery of English language.' 


\section{Feedback from attendees of MIE Research Week}

'This looks to be a challenge for your university but since it is known to students that English is one of the medium used for teaching, it will always be questionable to alternate in both English and French for assessments.'

'The alternate use of language does help particularly in teaching. In Mauritius, we are tuned to teaching a little in Kreol as well. I think the flexibility adapts to teaching but there will always be questions regarding assessment which remains formal and is a passport towards certifying proficiency in language as well.'

\section{Adopting a policy for Malagasy students to use the two official languages in the Mauritian educational system}

The last research question addressed to academic staff and feedback from attendees of the MIE research Week analysed whether there could be a policy of allowing Malagasy students to use two languages, English and French, in answering assessments and examinations.

'This could well apply to the UdM which is a bilingual institution. I am in favour of adopting it for Year 1 students.'

'Since formal examinations are less applicable to modern education and university assessments, there should be flexibility in adopting evaluations in two languages.'

'Since a policy has to be decided upon, I think that this concept must be formalised and a written evidence should be provided to academics so that they might allow Malagasy students to answer in the language of their choice.'

'The flexibility approach is important but why should it apply only to Malagasy students? What about a student from Ghana who speak just English at the UdM?'

\section{Feedback from attendees of MIE Research Week}

'Regarding making assessments flexibility by encouraging an alternate communication mode might be problematic. I fear if courses could be diluted and made easier for, say, one group of students, the Malagasy in comparison to Mauritian students.'

'This problem is likely to rise at the UdM or at any other institution willing to attract foreign students. Assessing in an ethnocentric environment like Mauritius compels us to impose the language that we demand. However, this problem should be justly dealt with in the future.'

'My comment is that in very country one goes, one needs to learn the native language. For example, in Russia, Russian has to be learnt and the same applies to Germany, etc. Since English is an international language, 
don't we perceive that the Malagasy student gets an advantage in learning English that will be of economic and cultural importance to them?'

\section{Limitations/delimitations of the research:}

This research limits itself to the environment of a single university. It is claimed that it purports what has been identified within a sample of students that the researcher has chosen for the exercise. This might not necessarily reflect the view and opinions of any foreign student or any Malagasy student as such. However, to correct certain errors and inaccuracies that might crop up in the research, the researcher has used evidences in the form of a technical review of assessment marks and findings from student class presentations. Further, the experience of working for the past three years with a growing number of foreign students could also overcome certain inherent weaknesses of the research sample.

\section{Discussion:}

The first research theme addressed the problem faced by Malagasy students in learning English language as they embarked on the existing courses at the UdM. The $\mathrm{p}$-value of the chi-square test 0.0148 revealed a significant difference between Year 1 and Year 2/3 students of the same group. This test proved that Year 1 intake of Malagasy students were not fully at ease with their new learning mode that was English-based. Some students shifted courses because of the difficulty that they encountered with English language. Others stated that lecturers should do an effort to make such learning more tailored to their needs. With maturing Malagasy students, it was seen that their difficulty was overcome through their experience at the $\mathrm{UdM}$ and they combined practice and personal effort to better assimilate English language. Nakatani (2010) supported this view by stating that learners can improve their speaking ability by developing learning strategies that enable them to become independent learners (Nakatani, 2010).

The second research theme focused on the current assessment undertaken at the UdM. In the chi-square test, the p-value was 0.243>0.05. There was no major significance between perceptions of assessment between the two groups under study. Similarity of perception arose from the fact that basic courses that were continuously assessed offered good opportunities to both group of students. Soft skills were better appreciated than formal examinations needing the mastery of English language. The only difference noted here was that there was emphasis on the part of Year2/3 students to accept that at higher levels, more proficiency of English language was needed and that they had to spare the effort to learn it. Littlewood (1984) commented that progress occured as a result of spontaneous, subconscious 
mechanisms, which are activated when learners are involved in communication with the second language.

The third research theme was targeted to UdM academics and conference participants of the MIE research Week. The theme aimed at identifying the possibility of tailoring some assessments so that they might be answered in French. Respondents from UdM who were involved in teaching and learning claimed that there might this possibility since the university is, since its inception a bilingual one. Krashen (1981) stated that the acquisition-learning distinction states that adults can develop competence in a second language in two distinct and independent ways: acquisition and learning. In Mauritian Law, for instance, there are two types of legislation in force and the Code Napoleon should be interpreted in French. On the part of MIE Conference participants who were new to this situation, they stated that this was a challenge for both the university and the students. There was some consensus in accepting that assessment flexibility might apply in the UdM case.

The fourth research theme was centred on a policy of making assessments bilingual and targeted to all groups that included Malagasy students. Lecturers of the UdM were in favour of adopting the policy but it should be made explicit for all staff. There were responses claiming that a university setting should allow for such a possibility. There was clear emphasis on developing a policy, formalising it and adapting to the situation at the UdM. On the part of conference attendees, the fear of course and assessment dilution was implicitly stated. One respondent confirmed that this scenario might affect other institutions attracting foreign students and the policy could be seriously envisaged. However, the statement of declaring a policy should not be overstated as one respondent said because learning the second language (L2) was an advantage that Malagasy students should consider when coming to learn and study in Mauritius. Scholars in education have stated that as learners' proficiency in the FL increases lexical similarity will allow for positive lexical transfer when students notice the minor differences between languages (Hu et al., 1982; Odlin, 1989).

\section{Conclusion:}

From the discussion, the main arguments gathered favour the targeting of assessments in a flexible way to Malagasy students studying at the UdM, especially first year intakes. Seen from the low grades scored by such students and a rate of failure that makes students repeat the first year, this research purports that there might be a possibility of allowing first year intakes from Malagasy Republic to write their assessments in French. This practice might be less applicable to Year 2 and 3 students who aim at better understanding and mastering English language. If the problem is not 
properly addressed, this might lead to discouragement from such students who now represent a viable target market for the UdM. Knowing that the $\mathrm{UdM}$ is a bilingual university that promotes teaching and learning in English and French medium, one language must not be however favoured to the detriment of the other one. So far, this problem limits itself to the possibility of making assessments flexible. In no way, it assumes that this initiative should be viewed as a favour made to first year intakes from Malagasy Republic nor should this be considered as a means of diluting the course content and examination process. This initiative is not yet in the form of a policy adopted at the UdM but must be duly considered as not to create some biased perception in terms of students' abilities in a university. Too often, bland perceptions like differences in level of education, proficiency and even culture could undermine the effort of better addressing assessments to the needs of a specified target market, in this case, Malagasy students.

To this extent, there must be possibilities to seek improvement from foreign learners in the immediate. For instance, to improve writing skills, academics must provide feedback for improvement (Storch, 2009). It might also be a question of social immersion that could partly address the problem namely through social groups (Rochecoutste et al, 2011). Moores and Popadiuck (2011) further state that interaction with host nationals, in this case, Mauritians, could be a means of encouraging students better express themselves in English. There is also group work that can improve communication competences like grammatical competence, sociolinguistic and strategic competence in English (Xue, 2013). These recommendations obviously follow the policy of tailoring assessments to foreign learners mentioned in the specific case of UdM.

\section{References:}

1. Amoh, K. (1984). Newly arrived foreign students at a U. S. university: Their adjustment difficulties and coping strategies. The University of Minnesota.

2. Antanaitis, C. (1990) Culture variances as they affect classroom performance and behaviour of foreign graduate students in education. The George Washington University.

3. Beasley, C. and Pearson, C. (1996) Reducing learning barriers amongst international students: A longitudinal developmental study, The Australian Educational researcher, Vol 23 No 2, Pp 79-96.

4. Betchoo, N. (2017) Adapting Assessment Methodology for Malagasy Students at The Université des Mascareignes, Conference Proceedings, MIE Research Week, 17-18 ${ }^{\text {th }}$ May 2017, Mauritius. 
5. Breuder, R. (1972) A statewide study: Identified problems of international students enrolled in public/community / junior colleges in Florida. The Florida State University.

6. Burke E. and Wyatt-Smith, C. (1996) Academic and nonacademic difficulties: Perceptions of graduate non-English speaking background students. Teaching English as a Second or Foreign Language, 2(1): 119.

7. Ganschow, L. and Schneider, E. (2006) Assisting Students with Foreign Language Learning Difficulties in School. From Perspectives on Language and Literacy, Special Edition 2006. Baltimore, MD: International Dyslexia Association.

8. Hu, Z.-Li., Brown, D., \& Brown, L. (1982) Some Linguistic Differences in the Written English of Chinese and Australian Students. Language Learning and Communication ,1(1).

9. Krashen, S. (1981) Second Language Acquisition and Second Language Learning. Oxford: Pergamon Press.

10. Leong, F., \& Sedlacek, W. (1989) Academic and career needs of international and United States college students. Journal of College Students Development, 30, 106-111.

11. Levai, Z., Koren, Z., and Vandor, T. (2009) Hungarian National Core Curriculum, Ministry of national resources, Hungary.

12. Mau, W-C., \& Jepsen, D. (1990) Help-seeking perceptions and behaviours: A comparison of Chinese and American graduate students. Journal of Multicultural Counselling and Development, 18 (2), 94-106.

13. Moores, L., \& Popadiuk, N. (2011) Positive aspects of international student transitions: A qualitative inquiry. Journal of College Student Development, 52(3), 291-306.

14. Nakatani,Y. (2010) Identifying strategies that facilitate EFL learners' oral communication: A classroom study using multiple data collection procedures. The Modern Language Journal, 94(1), 3468512.

15. Odlin, T. (2003) Cross-Linguistic Influence. In C. Doughty \& M. Long (Eds.), The Handbook of Second Language Acquisition. Oxford: Blackwell. p.39-49.

16. Pilote, A. (2007) Supporting success of international students in Canadian University. Higher Education Perspective, 3(2): 16-29.

17. Razavi, R. (1988). A study of the adjustment problems of international students in Northern Virginia community college, Prince George's Community College and Montgomery College. George Washington University. 
18. Rochecouste, J., Oliver, R., Mulligan, D., and Davies, M. (2011) The English Language Growth Project, Australian University Review. 53(1) 1020104.

19. Storch, N. (2011) The impact of studying in a second language (L2) medium university on development of L2 writing, Journal of Second Language Writing, 18, 103-118.

20. Welikala, T. (2015) Universities don't understand how international students learn, Higher Education Network.

21. Xue, M. (2013) Effect of group work on English communicative competence of Chinese international graduates in United States Institutes of Higher Education. The Qualitative Report, 18. 1-19. 